\title{
A Case of Spontaneous Rupture of the Uterus at the Eighth Month.
}

\author{
By V. B. Green Armytage, M.D., I.M.S., \\ Resident Surgeon, Eden Hospital, Calcutta.
}

Ar $12-30$ a.m. on July 15 of this year I was called to the Labour Room to see a Bengali primipara, aged 22, who had just been admitted in extremis.

The history given by the relatives was that two hours before, the patient had gone to the bathroom preliminary to retiring for the night. On straining she had felt something give in her belly; this was followed by great pain. She had vomited twice and then became semi-conscious. She was then brought into Hospital as quickly as was possible at that time of night.

On examination, I found the patient cold, bloodless and moribund. There was a soft, doughy tumour filling the abdomen, the size of a full-term pregnancy; fœetal parts were distinguishable, but heart sounds were absent. There was no definable foetal part in the pelvic brim. Per vaginam, there was no blood discharge; the cervix was not in the least taken up, and would not admit a finger. At $1 \mathrm{a.m}$. the patient died. I at once opened up the belly, and found a large quantity of freshly-clotted blood in the cavity, and floating among the intestines was a complete fœetal sac with the foetus in situ and the placenta entire on its outer surface. This sac was carefully removed entire and the blood sponged out of the cavity. I was then able to see a large 4 by $1 \frac{1}{2}$ inch rent at the fundus of the uterus. The whole uterus, which had retracted to its normal post partum size, was then removed. The accompanying drawing done by the artist attached to Professor Leonard Rogers's Museum will give a clearer conception of the rupture than any description.

The body was carefully surveyed for any signs of injury or syphilis, but with negative results; moreover, the relatives were absolutely certain neither had ever occurred. There was no history of any previous disease of any sort, barring occasional fever.

A portion of the uterine wall at the site of rupture was cut out for section, and the following is the report of Professor Leonard Rogers :- " The uterine wall at the site of rupture shows on microscopic section patches of marked hyaline degeneration, which is, however, irregularly distributed. Deep in the muscle structure there is some small-celled infiltration which is becoming organized in places into fibrous tissue." 


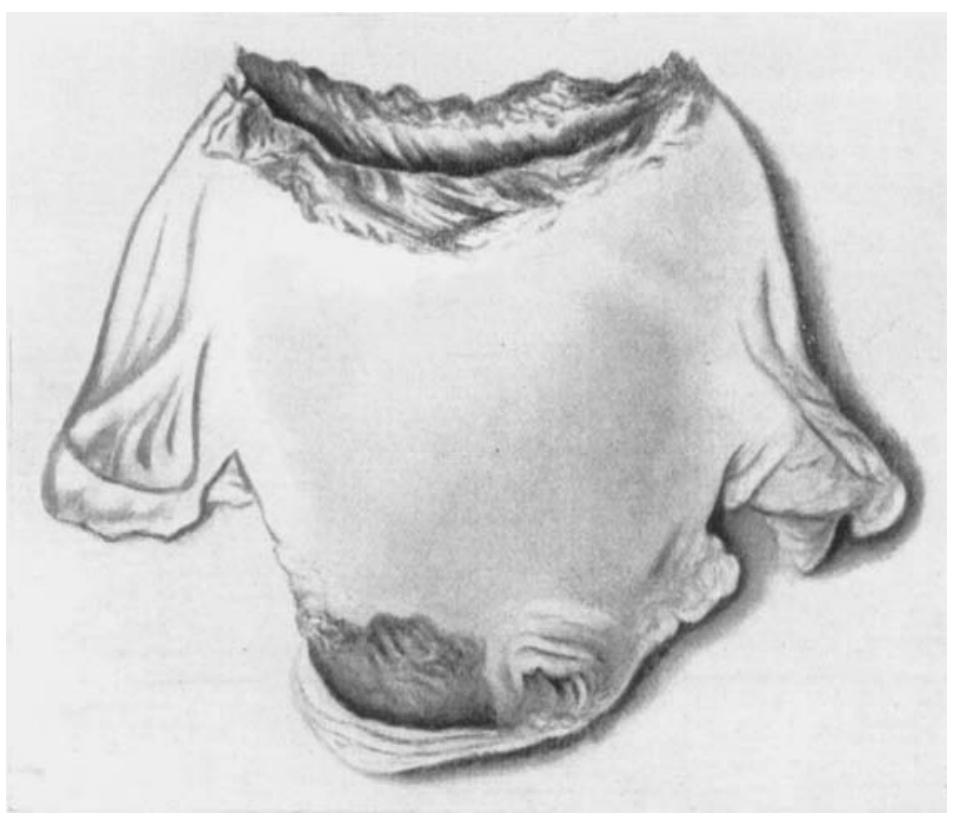

Spontaneous rupture at fundus of uterus. 
Baisch* has collected 78 cases of spontaneous rupture of the uterus. In 31 of his series the rupture occurred within the first five months of pregnancy. In 32 out of the 56 recorded the rupture was on either the posterior or anterior wall of the uterus.

In the above case I am reporting the site of rupture was almost immediately across the summit of the fundus. Beyond the fact that there was in some patches hyaline degeneration post mortem, combined with areas of fibrous tissue, there is to be found in this case, as in other similar recorded cases, no satisfactory cause or explanation.

After note.-The whole specimen has been sent to the Royal College of Surgeons Museum for acceptance.

- Baisch. Beiträge zu Geb. u. Gyn., 1903, vii, 248. 